\title{
Commentary \\ Recently published papers: Pseudomonas, brain and bowel injury and novel cardiac therapies
}

\author{
Uma M Bandarupalli and Gareth Williams
}

University Hospitals of Leicester NHS Trust, Infirmary Square, Leicester LE1 5WW, UK

Corresponding author: Gareth Williams, gareth.willaims@uhl-tr.nhs.uk

Published: 14 October 2008

This article is online at http://ccforum.com/content/12/5/184

(c) 2008 BioMed Central Ltd
Critical Care 2008, 12:184 (doi:10.1186/cc7019)

empirical antibiotic policies in VAP in the case of higher rates of VAP due to antibiotic-resistant bacteria.

In a second report, El Solh and colleagues [6] suggested that short-course ( $\leq 7$ days) antimicrobial therapy may not be adequate. The investigators studied the high mortality figures in Pseudomonas VAP and evaluated causes of microbial persistence in the alveolar space despite adequate antimicrobial therapy. They hypothesized that failure to eradicate $P$. aeruginosa from the lung is linked to type III secretory system isolates (cytotoxins indicating virulence). Thirty-four patients with $P$. aeruginosa VAP underwent noninvasive BAL at the onset of VAP and on day 8 after initiation of antibiotic therapy. Analysis for type III cytotoxins was undertaken and results indicated that about $50 \%$ of the patients had persistence of type III secretory system cytotoxins. The rest had full eradication, with undetectable levels of the cytotoxins. The persistence of the cytotoxins was attributed to the delay to eradication of the micro-organisms, and hence the recommendation is for longer courses of antimicrobial therapy.

Kollef and coworkers produced another report from the NASCENT trial [7], which is a multicentre randomized single blinded study including about 2,003 patients considered for the trial. The primary outcome was the incidence VAP by means of BAL fluid analysis at 24 hours. Patients were assigned to undergo intubation with one of two high-volume, low-pressure endotracheal tubes (ETTs), which were similar except for a silver coating on the experimental tube. The microbiologically confirmed rate of VAP in the treatment limb was $4.8 \%$ and that in the conventional limb was $7.5 \%$, with a relative risk reduction of $35.9 \%$. The investigators suggested that patients receiving a silver-coated ETT had a statistically significant reduction in the incidence of VAP and delayed time to VAP occurrence as compared with those receiving a similar, uncoated tube, although there was not much impact

$\mathrm{ALI}=$ acute lung injury; $\mathrm{APC}=$ activated protein $\mathrm{C} ; \mathrm{BAL}=$ bronchoalveolar lavage; $\mathrm{ETT}=$ endotracheal tube; $\mathrm{IAH}=$ intra-abdominal hypertension; $\mathrm{IAP}=$ intra-abdominal pressure; $\mathrm{ICU}=$ intensive care unit; $\mathrm{TBI}=$ traumatic brain injury; $\mathrm{VAP}=$ ventilator-associated pneumonia. 
on length of stay and overall mortality. Does this provide a rationale for using silver-lined ETTs in patients who are likely to require ventilation for longer than 24 hours?

Finally, we examine another paper published in Critical Care Medicine [8] dealing with outcome data from VAP patients with high bacterial loads. The authors investigated the frequency and outcomes of ventilated patients with newly acquired, large-burden infection with $P$. aeruginosa. They also verified the hypothesis that large bacterial loads were associated with adverse outcomes. A total of 69 patients were enrolled into the prospective study over a 4-year period who required more than 48 hours of mechanical ventilation and were identified as having newly acquired $P$. aeruginosa in their lower respiratory tracts. Daily surveillance cultures of endotracheal aspirates, Pseudomonas quantification and clinical signs of infection were analyzed. The results make for interesting reading. Forty-five out of 69 patients had high Pseudomonas burdens, but about one-third of these did not meet clinical criteria for VAP diagnosis but still had statistically significant higher risk for death (adjusted hazard ratio $=37.53$ ) as compared with the patients who had clinically diagnosed $P$. aeruginosa VAP. Furthermore, more patients with high $P$. aeruginosa burdens secreted the type III secretion facilitator protein PcrV, suggesting higher virulence. Is it time to revisit the clinical criteria for VAP diagnosis, with greater emphasis on quantification of respiratory tract bacterial load?

\section{Hyperventilation therapy after traumatic brain injury}

Neumann and coworkers reported data from the BrainlT database concerning use of hyperventilation strategies and adherence to Brain Trauma Foundation Guidelines after traumatic brain injury (TBI) in intensive care medicine [9]. This was a retrospective study of monitoring data from 22 European centres and involved 151 patients. The latest editions of the Brain Trauma Foundation Guidelines maintain a restricted use of hyperventilation for the treatment of TBI because of its negative impact on cerebral blood flow/ oxygenation and clinical outcome $[10,11]$. The study utilized data from nearly 8,000 blood gas analyses, representing ventilation episodes along with related minute by minute intracranial pressure data. Episodes were studied as under 24 hours or over 24 hours since TBI. Results from the study indicate that there was general adherence to guidelines except in cases of early prophylactic hyperventilation and cerebral oxygenation monitoring in forced hyperventilation. The authors suggest that, in the absence of elevated intracranial pressure, hyperventilation is better avoided; and that intentional reduction in arterial carbon dioxide tension to below $35 \mathrm{mmHg}$ has little supporting evidence.

\section{Acute lung injury}

Use of activated protein C (APC) in severe sepsis following the PROWESS and ADDRESS studies received a major boost throughout the world in all major ICUs. APC is a recognized adjunctive therapy in severe sepsis along with best standard care. It has been widely accepted that plasma protein $\mathrm{C}$ levels are low in patients with acute lung injury (ALI) (even without sepsis), with higher mortality/morbidity figures [12].

A report recently published in the American Journal of Respiratory and Critical Care Medicine [13] examined the efficacy of APC as a therapy for patients with ALI. American/ European consensus criteria for ALI were used to identify suitable patients, and those with severe sepsis and an Acute Physiology and Chronic Health Evaluation II score of 25 or greater were excluded. The primary end-point was ventilatorfree days. Eligible patients were randomly assigned to either receive APC or placebo (double blinded) within 72 hours. The results revealed that the APC-treated group had increased plasma protein $\mathrm{C}$ levels and decreased pulmonary dead space fraction, but sadly this did not translate into clinical benefit, there being no difference in the number of ventilator-free days between the two groups. Hence, the investigators concluded that APC did not improve outcomes from $A L I$ in the absence of severe sepsis and high disease severity.

\section{Current affairs in ischaemic heart disease}

Results from BEAUTIFUL [14], a randomized, double-blind, placebo-controlled trial evaluating the use of ivabradine for patients with stable coronary artery disease and left ventricular systolic dysfunction, were recently published in the Lancet.

Ivabradine specifically inhibits the If current in the sinoatrial node to lower heart rate. Fox and coworkers [14] exploited this effect of the drug in more than 10,000 patients with stable coronary artery disease and left ventricular ejection fraction less than $40 \%$ recruited over 2 years. The primary end-point was a composite of cardiovascular death, admission to hospital for acute myocardial infarction and admission to hospital for new onset or worsening heart failure. The results indicated that the drug did not improve primary endpoints but improved secondary end-points. The investigators suggested that use of the drug in patients with higher heart rates (more than 70 beats/minute) reduced the incidence of coronary artery disease outcomes.

'On-TIME 2' data were also recently published in the Lancet [15]. This was a multicentre, double-blind trial including 984 patients, who were randomly assigned to receive tirofiban (Gpllb/llla inhibitor) and placebo. The primary end-point was the extent of residual ST-segment deviation 1 hour after percutaneous coronary intervention. The study identified significant benefit from prehospital use of tirofiban in patients with acute ST-segment elevation myocardial infarction undergoing primary coronary angioplasty (percutaneous coronary intervention). 


\section{Acute bowel injury}

Reintam and coworkers [16] reported findings from a study in which they evaluated the differential impact of primary and secondary intra-abdominal hypertension (IAH) on outcomes in intensive care medicine. This was a prospective study of 257 mechanically ventilated patients deemed to be at considerable risk for development of IAH. These patients underwent repeated measurements of intra-abdominal pressure (IAP) during their ICU stay and were followed up to 90-day survival. The authors incorporated the new consensus definitions recently established by the World Society of the Abdominal Compartment Syndrome [17].

- IAH is sustained or repeated pathological elevation of IAP to $12 \mathrm{mmHg}$ or greater.

- Abdominal compartment syndrome is sustained IAP above $20 \mathrm{mmHg}$ along with a new organ dysfunction.

- Primary IAH is a condition associated with injury or disease in the abdomino-pelvic region that frequently requires early surgical or interventional radiological intervention (for example, peritonitis, pancreatitis, bowel disease, or abdominal trauma).

- 'Secondary IAH' refers to conditions that do not originate from the abdomino-pelvic region (for example, sepsis/ shock, polytrauma, cardiopulmonary disease, intoxications, or burns).

$\mathrm{IAH}$ developed in 95 patients (37.0\%) with primary IAH $(n=60)$ and secondary IAH $(n=35)$ [16]. Patients with secondary IAH exhibited a significant increase in mean IAP during the first 3 days, whereas IAP decreased in the patients with primary $\mathrm{IAH}$. The patients with $\mathrm{IAH}$ had a significantly higher mortality compared with patients without the syndrome. The authors concluded the following: secondary $\mathrm{IAH}$ is less frequent, has a different time course and worse outcome; IAH was an independent predictor of ICU adverse outcome; and ICU patients with two or more risk factors should undergo daily IAP measurement.

This study was accompanied by an excellent editorial review [18] that highlighted the importance of understanding the mechanism of injury in IAH/abdominal compartment syndrome. The review also proposed the concept of acute bowel injury and acute intestinal distress syndrome. Clearly, much work needs to be done in this area.

\section{Competing interests}

The authors declare that they have no competing interests.

\section{References}

1. American Thoracic Society \& Infectious Diseases Society of America: Guidelines for the management of adults with hospital-acquired, ventilator-associated, and healthcare-associated pneumonia. Am J Respir Crit Care Med 2005, 171:388-416.
2. Tejerina E, Frutos-Vivar F, Restrepo MI, Anzueto A, Abroug F, Palizas F, González M, D'Empaire G, Apezteguía C, Esteban A, Internacional Mechanical Ventilation Study Group: Incidence, risk factors, and outcome of ventilator-associated pneumonia. $J$ Crit Care 2006, 21:56-65.

3. Rello J, Ollendorf DA, Oster G, Vera-Llonch M, Bellm L, Redman R, Kollef MH, VAP Outcomes Scientific Advisory Group: Epidemiology and outcomes of ventilator-associated pneumonia in a large US database. Chest 2002, 122:2115-2121.

4. Iregui M, Ward S, Sherman G, Fraser VJ, Kollef M: Clinical importance of delays in the initiation of appropriate antibiotic treatment for ventilator associated pneumonia. Chest 2002, 122:262-268.

5. Kollef KE, Schramm GE, Wills AR, Reichley RM, Micek ST, Kollef $\mathrm{MH}$ : Predictors of 30-day mortality and hospital costs in patients with ventilator-associated pneumonia attributed to potentially antibiotic-resistant gram-negative bacteria. Chest 2008, 134:281-287.

6. El Solh AA, Akinnusi ME, Wiener-Kronish JP, Lynch SV, Pineda LA, Szarpa K: Persistent infection with Pseudomonas aeruginosa in ventilator-associated pneumonia. Am J Respir Crit Care Med 2008, 178:513-519,

7. Kollef MH, Afessa B, Anzueto A, Veremakis C, Kerr KM, Margolis BD, Craven DE, Roberts PR, Arroliga AC, Hubmayr RD, Restrepo MI, Auger WR, Schinner R; NASCENT Investigation Group: Silver-coated endotracheal tubes and incidence of ventilatorassociated pneumonia: the NASCENT randomized trial. JAMA 2008, 300:805-813

8. Zhuo H, Yang K, Lynch SV, Dotson RH, Glidden DV, Singh G, Webb WR, Elicker BM, Garcia O, Brown R, Sawa Y, Misset B, Wiener-Kronish JP: Increased mortality of ventilated patients with endotracheal Pseudomonas aeruginosa without clinical signs of infection. Crit Care Med 2008, 36:2495-2503.

9. Neumann JO, Chambers IR, Citerio G, Enblad P, Gregson PA, Howells T, Mattern J, Nilsson P, Piper I, Ragauskas A, Sahuquillo $\mathrm{J}$, Yau $\mathrm{YH}$, Kiening K: The use of hyperventilation therapy after traumatic brain injury in Europe: an analysis of the BrainlT database. Intensive Care Med 2008 34:9.

10. Bullock MR, Chesnut RM, Clifton GL, Ghajar J, Marion DW, Narayan RK, Newell DW, Pitts LH, Rosner MJ, Walters BC, Wilberger JE: Management and prognosis of severe traumatic brain injury. Part I: guidelines for the management of severe traumatic brain injury. J Neurotrauma 2000, 17:513-520.

11. Bullock MR, Povlishock JT: Guidelines for the management of severe traumatic brain injury. J Neurotrauma 2007, 24(suppl 1):587-590.

12. Ware LB, Fang $X$, Matthay MA: Protein $C$ and thrombomodulin in human acute lung injury. Am J Physiol Lung Cell Mol Physiol 2003, 285:L514-L521.

13. Liu KD, Levitt J, Zhuo H, Kallet RH, Brady S, Steingrub J, Tidswell M, Siegel MD, Soto G, Peterson MW, Chesnutt MS, Phillips C, Weinacker A, Thompson BT, Eisner MD, Matthay MA: Randomized clinical trial of activated protein $\mathrm{C}$ for the treatment of acute lung injury. Am J Respir Crit Care Med 2008, 178:618623.

14. Fox K, Ford I, Steg PG, Tendera M, Ferrari R; BEAUTIFUL Investigators: Ivabradine for patients with stable coronary artery disease and left-ventricular systolic dysfunction (BEAUTIFUL): a randomised, double-blind, placebo-controlled trial. Lancet 2008, 372:807-816.

15. Van't Hof AW, Ten Berg J, Heestermans T, Dill T, Funck RC, van Werkum W, Dambrink JH, Suryapranata $\mathrm{H}$, van Houwelingen G, Ottervanger JP, Stella P, Giannitsis E, Hamm C; Ongoing Tirofiban In Myocardial infarction Evaluation (On-TIME) 2 study group: Prehospital initiation of tirofiban in patients with STelevation myocardial infarction undergoing primary angioplasty (On-TIME 2): a multicentre, double-blind, randomised controlled trial. Lancet 2008, 372:537-546.

16. Reintam A, Parm P, Kitus $R$, Kern H, Starkopf J: Primary and secondary intra-abdominal hypertension different impact on ICU outcome. Intensive Care Med 2008, 34:9.

17. World Society of the Abdominal Compartment Syndrome Consensus Guidelines Summary [http://www.wsacs.org/consensus_summary.php]

18. Malbrain ML, De Laet I: AIDS is coming to your ICU: be prepared for acute bowel injury and acute intestinal distress syndrome. Intensive Care Med 2008, 34:1565-1569. 